\title{
In Control or Fatalistically Ruled? The Sense of Mastery among Working Canadians
}

\author{
Scott Schieman and Atsushi Narisada
}

Version Post-Print/Accepted Manuscript

Citation Schieman, Scott and Atsushi Narisada. 2014. "In Control or

(published version) Fatalistically Ruled? The Mastery among Working Canadians." Canadian Review of Sociology 51(4):343-374.

Publisher's Statement This is the peer reviewed version of the following article: Schieman, Scott and Atsushi Narisada. 2014. "In Control or Fatalistically Ruled? The Mastery among Working Canadians." Canadian Review of Sociology 51(4):343-374, which has been published in final form at https://dx.doi.org/10.1111/cars.12051. This article may be used for non-commercial purposes in accordance with Wiley Terms and Conditions for Self-Archiving.

\section{How to cite TSpace items}

Always cite the published version, so the author(s) will receive recognition through services that track citation counts, e.g. Scopus. If you need to cite the page number of the TSpace version (original manuscript or accepted manuscript) because you cannot access the published version, then cite the TSpace version in addition to the published version using the permanent URI (handle) found on the record page. 


\section{In Control or Fatalistically Ruled? The Sense of Mastery among Working Canadians* SCOTT SCHIEMAN ATSUSHI NARISADA University of Toronto}

* Direct correspondence to Scott Schieman, Department of Sociology, 725 Spadina Avenue, University of Toronto, Toronto, ON M5S 2J4 Canada (scott.schieman@utoronto.ca). A grant award from the Canadian Institutes of Health Research (CIHR) supports this study (Funding Reference Number: MOP-102730; Scott Schieman, P.I).

Running Head: Work Conditions Work-Family Interface and the Sense of Mastery

Key words: mastery, sense of control, socioeconomic status, work-family interface, Job DemandsResources Model, work-family conflict 


\begin{abstract}
Using data from a 2011 nationally representative sample of Canadian workers $(\mathrm{N}=5,576)$, the present study evaluates the social-structural determinants of the sense of mastery. Three main contributions emerge. First, we document that each of the main components of socioeconomic status - education, income, occupation, and economic hardship - have distinct total, indirect, and net associations with mastery. The well-educated report more mastery because of their higher earnings - but exposure to more role blurring and work-family conflict offset what would otherwise be their even higher levels of mastery. Second, job-related demands and resources have largely independent associations with mastery, but our analyses also reveal some key areas of overlap. Third, role-blurring activities - and their connections with work-to-family conflict and family-towork conflict — offer unique expansions to the overall narrative of mastery, with unexpected explanatory and suppression effects. We interpret each of these observations in an effort to advance recent theoretical perspectives about mastery.

\section{RÉSUMÉ}

À partir de données recueillies en 2011 auprès d'un échantillon représentatif national de travailleurs canadiens $(n=5,576)$, cette étude examine les déterminants sociostructurels de la maitrise de soi. Trois principales contributions découlent de cette étude. Premièrement, chaque composante du statut socioéconomique, soit l'éducation, le revenu, la profession de même que la précarité économique, a une association distincte et indirecte avec la maitrise de soi. Par exemple, les travailleurs instruits ressentent un plus grand sentiment de maitrise de soi dû à leur revenu supérieur. Toutefois, l'ambigüité de rôle et le conflit travail-famille, plus fréquents chez ces derniers, atténuent cette relation. Deuxièmement, les demandes et les ressources liées au travail sont indirectement associées avec la maitrise de soi. Cependant, nos analyses démontrent que certains secteurs importants se chevauchent. Troisièmement, les liens entre les secteurs d'activités pour lesquelles il y a ambigüité de rôle et les conflits travail-famille et les conflits famille-travail permettent de mieux comprendre le concept de maitrise de soi chez les travailleurs canadiens. Nos analyses démontrent des effets inattendus explicatifs et de suppression. Nous interprétons chacune des ces observations en vue de faire avancer les perspectives théoriques récentes en ce qui a trait à la maitrise de soi.
\end{abstract}




\section{In Control or Fatalistically Ruled? The Sense of Mastery among Working Canadians}

In their classic 1978 paper titled "The Structure of Coping," Pearlin and Schooler defined the sense of personal mastery as "the extent to which one regards one's life chances as being under one's own control in contrast to being fatalistically ruled" (p. 5). Since then, decades of scholarship have articulated the relevance of the sense of mastery as a mediating and moderating resource in the stress process (Mirowsky and Ross 2003a; Pearlin, Schieman, Fazio, and Meersman 2005; Pearlin and Bierman 2013; Pudrovska, Schieman, Pearlin, and Nguyen 2005; Low, Keating, and Gao 2009). Given the importance of mastery for health and well-being, sociologists have also sought to document its social-structural antecedents and influences (Kohn 1976; Seeman 1967; Pearlin, Nguyen, Schieman, and Milkie 2007), including studies based on samples from Toronto (Turner and Lloyd 1999) and Southwestern Ontario (Schieman and Turner 1998).

As Ross and Mirowsky (2013) observe, "beliefs about personal control are often realistic perceptions of objective conditions" (p. 383). In the search for the determinants of mastery, researchers have concentrated on objective conditions that relate directly or indirectly to socioeconomic status - especially education — and the nature of working life (Mirowsky and Ross 2003b; Ross and Wright 1998; Schieman and Plickert 2008). The present study expands prior research on the social-structural determinants of the sense of mastery in two ways. First, using data from a 2011 national survey of Canadian workers, we elaborate on earlier discoveries among Americans of the patterns in mastery across socioeconomic status (SES): education, income, occupation, and economic hardship (Mirowsky and Ross 2003a, 2003b). Further, we advance a more comprehensive account of the relevance of conditions in the workplace- job demands and resources - and key facets of the work-family interface, especially role blurring activities and workfamily conflict. We find that the relationship between SES and mastery is complex and riddled with 
suppressions, suggesting that earlier research has under-estimated the complexity of the model. Collectively, our analyses advance new knowledge about mastery by describing a broader portrait of the social conditions and interrelationships that shape it.

\section{BACKGROUND AND THEORETICAL FRAMEWORK}

Before describing our guiding theoretical framework, we provide some background about the economic climate in Canada at the time of our data collection to situate our analyses within in a broader socioeconomic context. First and foremost, the unemployment rates in Canada in 2010 and 2011 - during the period of data collection for the current study were collected - were 8.0 percent and 7.4 percent, respectively (Employment and Social Development Canada 2014). Due to the global financial crisis in 2008, the unemployment rate reached its highest point since 1998 in 2009 with 8.3 percent. The average unemployment rate from 1999 through 2013 was 7.15 percent (Employment and Social Development Canada 2014; Statistics Canada 2014). Thus, relatively high unemployment rates in 2010 and 2011 reflect the effects of the financial crisis. These statistics, however, are lower than that of the United States, which had unemployment rates of 9.63 percent and 8.93 percent in 2010 and 2011, respectively (U.S Bureau of Labor Statistics, 2014). Moreover, according to the Department of Finance Canada (2014), the Canadian economy after the 2008 crisis represents "the strongest labor market performance among all G-7 economies" (p. 3). Compared to other G-7 economies, the Canadian economy has expanded at a faster pace and with higher levels of job creation. Although the Canadian economy was affected by the financial crisis with the rise in unemployment rate, its economy has been relatively stable in comparison to other G-7 nations.

With this broader macro-level economic climate in mind, we now proceed to a detailed account of our overarching conceptual framework to examine the more micro-level experiences of Canadian workers and the link to the sense of mastery. Several core propositions in the literature 
contribute to the content and organization of this schema. Among them, Ross and Mirowsky's

(2013) theoretical and empirical efforts provide foundational insights:

"Belief in external control is the learned and generalized expectation that one has little control over meaningful events and circumstances in one's life. As such, it is the cognitive awareness of a discrepancy between one's goals and the means to achieve them. Theoretically, social structural positions indicative of objective powerlessness, including dependency, disorder, structural inconsistency, role stress, and alienated labor, increase the probability of this discrepancy and thus increase perceived powerlessness" (p. 383).

These statements offer direct assertions about the particular ways that social structural positions are influential for mastery, first drawing explicit connections to different dimensions of SES and then tracing pathways via the nature of work conditions and features of the work-family interface. In the sections below, we extend these ideas to propose a series of hypotheses and a rationale for each. Figure 1 illustrates the conceptual framework of our analyses.

[INSERT FIGURE 1 ABOUT HERE]

\section{A Fundamental Antecedent: Socioeconomic Status}

Of all the indicators of social structural position in society, education has emerged as a cornerstone and fundamental antecedent of the sense of mastery. Community- and population-based studies consistently document that higher levels of education are associated with greater mastery (Ross and Mirowsky 2013; Schieman 2001; Turner and Lloyd 1999). Education shapes mastery indirectly through its influence on a set of "allocation processes" (Schieman and Plickert 2008). First and foremost, education is a critical determinant of participation in the labor force, occupational status, earnings, and position in organizational hierarchies (Kerchkhoff, Raudenbush, and Glennie 2001). Moreover, these structural features are often linked with self-directed work and job resources such as schedule control, autonomy, and challenging work (Kohn and Schooler 1982; 
Ross and Reskin 1992; Tausig and Fenwick 2011). Some of education's potency is also connected to credentialism. As Hunter (1988) observes: "educational credentials are convenient markers for employers of the suitability of potential employees for jobs at different levels of autonomy, responsibility, or self-direction" (p. 753). Advanced education might also symbolize character traits such as competence and persistence that are often valued in the labor market (Becker 1993).

In sum, education is a determinant of occupational position and its associated social and economic advantages and disadvantages (Pallas 2003; Ross and Wright 1998). Collectively, these factors contribute to opportunities for enhanced sense of potency and causal effectiveness (Mirowsky and Ross 2003a; Pearlin et al. 2005; Ross and Mirowsky 1992; Ross and Wright 1998; Schieman and Plickert 2008). We draw upon these ideas to propose the following hypotheses. First and foremost, as numerous others have demonstrated, we expect to replicate the positive association between education and the sense of mastery. Second, higher earnings, higher occupational status, and lower economic hardship among the well-educated should contribute to that positive association. Third, each form of SES may be associated with mastery indirectly through their associations with job demands and resources (described in detail below) - that is, these job attributes should mediate the relationship between SES and mastery.

\section{Social-Structural Positions: Job-Related Demands versus Resources}

Given the hypothesized centrality of job attributes as mediators, in this section we elaborate on their potential relevance. For this effort, we draw upon the ideas embedded in the classic Job Demands-Control model (JD-C) and the more recent Job Demands-Resources model (JD-R)—both models are designed to evaluate the influence of job-related demands and resources for strains and health outcomes (Bakker and Demerouti 2007; Karasek 1979). Job demands are defined as "those physical, psychosocial, or organizational aspects of the job that require sustained physical and/or 
mental effort and are, therefore, associated with certain physiological and/or psychological costs (Bakker and Geurts 2004). In the JD-R model, job demands are identified as potentially problematic for workers, especially in the "health impairment process" (Demerouti and Bakker 2011).

In the present study, we evaluate three distinct but interrelated job demands: (a) excessive pressure, (b) long work hours, and (c) work hours mismatch. To varying degrees, these demands represent "strains" that can tax workers' limited time, energy, and resources. We integrate Ross and Mirowsky's (2013) proposition that role stress is a key determinant of mastery with the JD-R model's claim that job demands exact psychological costs. This contributes to the demands hypothesis: Each of these three demands should be negatively (and independently) associated with mastery. Among these demands, we suspect that job pressure represents the most potent threat because it represents a dissonance between the quantity of work and the time allotted for it (Duxbury et al. 2008). However, both long work hours and hours mismatch also exemplify potentially problematic conditions; long hours represent a way that jobs extract excessive amounts of individuals' limited time, while hours mismatch reflects an appraisal and preference related to role strain (Böheim and Taylor 2004; Otterbach 2010; Wooden, Warren, and Drago 2009).

By contrast, the other core feature of the JD-R model—job resources—are defined as "physical, psychosocial, or organizational aspects of the job that may be functional in meeting task requirements (i.e., job demands) and may thus reduce the associated physiological and/or psychological costs — and at the same time stimulate personal growth and development" (Bakker and Geurts, 2004:348). The concept of job resources partly evolves from Karasek's (1979) notion of job control: "the working individual's potential control over his tasks and his conduct during the working day" (p. 289). Early versions of JD-C model focused mainly upon decision latitude, which has two components: "skill discretion" and "decision authority" (Karasek and Theorell, 1990). According to Karasek et al. (1998), skill discretion involves "the level of skill and creativity 
required on the job and the flexibility permitted the worker in deciding what skills to employ," while decision authority entails the "organizationally mediated possibilities for workers to make decisions about their work" (p. 323). These themes endure in the JD-R model's conceptualization of resources (Bakker and Demerouti 2007; Schaufeli and Taris 2014). In the present analyses, we build upon this conceptual frame of job resources by assessing a broader class of conditions that includes control over one's own work (job autonomy), control over the timing of work (schedule control), control over others' work (job authority), and control as reflected in challenging or creative activities that involve skill utilization (challenging work).

Most analyses of the JD-C and JD-R models have concentrated on the ways that resources moderate the relationship between job demands and negative outcomes (Beehr, Glaser, Canali, and Wallwey 2001; Schaufeli and Taris 2014). Little is known, however, about the independent influences of these resources on the sense of mastery — net of and in combination with job-related demands and stress in the work-family interface. We assess the impact of four job resources that align with the classic conceptualization of job control: autonomy, schedule control, challenging work, and authority (Schieman 2013; Tausig and Fenwick 2011). As a group, these forms of job control and resources are directly contrary to "alienated labor" (Marx [1852] 1983) — that is, "a condition under which the worker does not decide what to produce, does not design and schedule the production process, and does not own the product" (Ross and Mirowsky 2013:384). Instead, collectively these job resources should enhance workers' realization of a stronger connection between their own goals and the means to achieve them. Each represents a fundamental feature of social structural position that might enhance the sense of causal effectiveness and instrumentalism (Ross and Mirowsky 1992; Ross and Wright 1998; Schieman and Plickert 2008). Taken together, these ideas contribute to the resource hypothesis prediction that schedule control, job autonomy, job authority, and challenging work should be positively and independently associated with mastery. 
Stress in the Work-Family Interface: Role Blurring and Conflict

As Figure 1 illustrates, we hypothesize that the influence of job demands and resources on mastery are channeled indirectly through conditions in the work-family interface. In this section, we articulate two main pathways and our rationale for them. First, we assess the relevance of what some scholars have referred to as "role-blurring" (Glavin and Schieman 2010; Voydanoff 2007), which is comprised of three dimensions: (a) work contact - the extent that individuals send and receive work-related communications (e.g., emails, phone calls, text messages) outside of regular work hours; (b) family contact - the extent that individuals contact or are contacted by family members while they are at work; and (c) work-family multitasking - the extent that individuals simultaneously engage in work- and family-related activities while they are at home. Collectively, these processes represent potentially problematic activities in the work-family interface, especially when they generate interruptions or interference that contribute to work-to-family conflict (WFC) or family-to-work conflict (FWC). Both directions of conflict involve the extent that individuals perceive that work/family hampers responsibilities and expectations of the other domain, and competes for individuals' finite amounts of time and energy (Greenhaus and Parasuraman 1987; Wallace and Young 2010; Wallace 2013). WFC/FWC increases when role-related pressures from one domain are incompatible with and undermine role quality and performance in the other domain.

Among the three forms of role blurring, work contact may have the most potent - and complex - association with mastery for several reasons. The proliferation of communication technologies across workplaces (and in society more generally) has created new strains in the borders between work and non-work life (Milliken and Dunn-Jensen 2004). Expanded access to email, cell phones, and other "smart phone" devices can enhance flexibility, enable remote work, and increase the sense of choice or control over when and where work is completed—but it also contributes to a "24/7 availability" that may present unanticipated challenges (Batt and Valcour 
2003; Chesley 2005). Here, we draw upon Border Theory, which emphasizes a downside of these processes: The ways that these devices foster the completion of work beyond the typical spatial and temporal boundaries of the workplace facilitates the extent that work might spillover into other spheres of life (Boswell and Olson-Buchanan 2007; Clark, 2000; Valcour and Hunter 2005). Work contact represents a "boundary-spanning demand" that blurs the temporal, physical, and psychological boundaries that separate work and non-work life. This has implications for permeability - that is, the degree to which aspects of one domain are able to enter other domains (Voydanoff 2007). Greater permeability may also elevate exposure to family contact and workfamily multitasking (Schieman and Young 2010a; Voydanoff 2007). Taken together, these roleblurring activities increase the risk of conflict between work and family domains (Chesley 2005; Schieman and Glavin 2008).

Based on these ideas, we test two interrelated hypotheses about the ways that these features of the work-family interface influence mastery and the relevance of job demands and resources. Specifically, the demand hypothesis predicts (a) that work-family role blurring and WFC/FWC is negatively associated with mastery, and (b) that part of the influence of role blurring on mastery occurs indirectly through WFC/FWC. By contrast, the resource hypothesis predicts that job resources should buffer any negative associations between role blurring or WFC/FWC and mastery.

\section{A Complementary Perspective: The Stress of Higher Status}

We test an emerging thesis - the stress of higher status - that builds on the predictions of the demands and resources hypotheses and integrates the work-family interface processes outlined above (Schieman, Milkie, and Glavin 2009). This view underscores that some job demands and work-family stress are patterned in ways contrary to conventional expectations about the negative relationship between SES and stress exposure or poorer mental health outcomes (McLeod 2013; 
Schieman 2013; Schieman and Reid 2009). In our analyses, the stress of higher status hypothesis extends to the implications of such patterns for levels of mastery and the ways that these work conditions and stressors in the work-family interface might be influential.

First and foremost, the stress of higher status hypothesis begins with education because of its association with higher levels of demands like excessive job pressure (Schieman 2013), work hours mismatch—especially excess work hours, or working more hours than preferred (Lyness et al. 2012), and WFC (Schieman and Glavin 2008; 2011). As the demands hypothesis predicts, each of these conditions is expected to erode mastery. However, the stress of higher status hypothesis extends that view to predict that these counterbalancing effects should mask or conceal education's positive association with mastery. In analytical terms, when we "hold constant" these job demands, we should observe even greater education-based differences in mastery. Such observations would indicate that greater levels of stress exposure among the well-educated offset the otherwise more favorable consequences of education for mastery. Stated simply: Some kinds of stressors that come with higher status may dampen or detract from the psychosocial rewards of higher status.

These stress of higher status predictions and suppression patterns should also be relevant for income and higher status occupations - given that evidence also links them to more job pressure, longer work hours, and more WFC (Jacobs and Gerson 2004; Maume and Bellas 2001; Moen and Yu 2000; Schieman 2013; Schieman et al. 2006; Walters and Denton 1995). Moreover, the stress of higher status thesis extends beyond SES to include job-related resources: It flips the "resource" concept by identifying the ways that some job resources are associated with more responsibilities and greater exposure to particular stressors. The implication is that some job resources tend to "behave" more like demands in the ways that they predict stress in the work-family interface. Of the four classic forms of job control, job authority and challenging work are exemplars. Ross and Mirowsky (1992) posit that although job authority "represents an aspect of the ability to achieve 
one's ends through the job, ...the corresponding responsibility for the actions and performance of others cancels any gain in the overall sense of control" (p. 220). Recent empirical tests of that claim demonstrate that the 'downsides' of job authority — especially interpersonal conflict and workfamily conflict — offset the 'upsides' and contribute to an overall null association between job authority and health (Schieman and Reid 2009). Similarly, other studies reveal that individuals with more challenging work would report even less WFC were it not for their higher levels of job demands, work contact, and multitasking (Schieman and Glavin 2011; Schieman and Young 2010a). In the present study, we evaluate whether or not these same kinds of patterns suppress the predicted positive influences of job authority and challenging work on levels of mastery.

\section{METHODS}

Sample

To test the hypotheses outlined above, we analyze data from the 2011 Canadian Work Stress and Health study (CAN-WSH), a national sample of the Canadian labor force. This is a primary data collection effort for which we hired the survey house R.A. Malatest and Associates. The interview questions are primarily modeled on those from other large national surveys (e.g., the National Study of the Changing Workforce). Interviews were conducted by telephone between January and August 2011. To be eligible to participate in the study, individuals had to be: (1) residing in Canada; (2) 18 years of age or older; (3) currently working at a paid job or operated an income-producing business; (4) employed in the civilian labor force; and 5) live in a noninstitutional residence. In households with more than one eligible person, we used the "next birthday" method to randomly select a study participant. Calls were made to a regionally stratified unclustered random probability sample generated by random-digit-dial methods. Interviews were conducted in English or French and averaged approximately 30-35 minutes. Study participants 
received a \$20 gift card for completing the interview. The final full sample was 6,004 , with a response rate of approximately 40 percent. ${ }^{1}$ For our analyses in this paper, we excluded cases with missing values on the focal study variables and weighted the data according to the most recent Canadian Census information on the gender, age, marital status, and education profile of the population. This yields an effective sample of 5,576 for all analyses.

\section{Dependent Measure: The Sense of Mastery}

We use four items to measure mastery (Pearlin and Schooler 1978). These items ask study participants the extent that they agree or disagree with the following statements: "You have little control over the things that happen to you," "There is really no way you can solve some of the problems you have," "You often feel helpless in dealing with problems of life," and "Sometimes you feel that you are being pushed around in life." Response choices are "strongly disagree" (1), "somewhat disagree" (2), "somewhat agree" (3), and "strongly agree" (4). We reverse-coded the items and averaged responses to create the index; higher scores indicate a greater mastery $(\alpha=.72)$.

\section{Socioeconomic Status}

We use four separate indicators of SES: education, income, occupation, and economic hardship. Education contrasts "high school or GED" with "less than high school," "associate/2-year

\footnotetext{
${ }^{1}$ Some readers might have concerns about the response rate. Although a potential problem associated with lower response rates is nonresponse bias in estimates (Babbie 2007), recent research has challenged the link between response rates and nonresponse bias (see Groves 2006; Curtin et al. 2000; Merkle and Edelman 2002). Nevertheless, we address the possibility that results were unduly influenced by nonresponse bias. In order to do this, we compared results from unweighted and weighted analyses in which we weighted the sample based on a key demographic statuses (e.g. gender, age, marital status, education). We found few differences between the weighted and unweighted results. Winship and Radbill (1994) argue that controlling for characteristics on which individuals may be under- or over-sampled adjusts for biases due to these characteristics; all analyses include controls to adjust for this potentiality. Nonresponse bias should not a major problem for the estimates being reported. As two points of comparison with other surveys on work and stress, the 2008 National Study of the Changing Workforce achieved 55 percent. In the 2001 National Work-Life Conflict Study of Canadian workers, Duxbury and Higgins report the following: "Approximately 120,000 surveys were sent out. At the time of data analysis, we had received 31,571 usable responses for a response rate of approximately 26\%." Thus, the CAN-WSH falls between the 2008 NSCW and the 2001 National Work-Life Conflict study.
} 
degree," "some college, no degree earned," "4-year university degree," or "graduate or professional degree (MA/Ph.D.)" One item assesses total personal earnings in the previous year-from all sources. We used the following categories: "\$25,000 or less," " $\$ 25,001$ to $\$ 50,000$, , "\$50,001 to $\$ 75,000$," “\$75,001 to $\$ 100,000$, , “\$100,001 or more.” We use the modal category ( $\$ 25,001$ to $\$ 50,000)$ as the reference group. To assess whether or not the participant is in a higher status occupation, we ask: "What kind of work do you do? That is, what is your occupation?" Using the open-ended information provided, occupations are coded into thirty-three categories using the 2006 Canadian National Occupation Classification. Codes are then collapsed into seven main categories in accordance with the 1990 US census standard occupational classification system. Analyses compare higher status occupations ("executive" or "professional") with a category that combines all others ("technical," "service," "sales," "administrative" and "production"). We followed these specific procedures in an effort to make these data more comparable with US-based studies.

Economic hardship is assessed with three items. The first two ask about the frequency in the past year of "having trouble paying the bills" and "not having enough money to buy food, clothes, or other things your household needed." Response choices are coded: "never" (1), "rarely" (2), "sometimes" (3), "often" (4), and "very often" (5). A third item asks: "How do your finances usually work out by the end of the month?" Response choices are coded: "a lot of money left over" (1), "a little money left over" (2), "just enough to make ends meet" (3), and "not enough to make ends meet" (4). We standardized the three items because of their different response choices and averaged them; higher scores indicate more economic hardship $(\alpha=.76)$.

\section{Job-Related Demands}

Long work hours. We compare individuals who work 50 hours or more per week (dummycoded 1) with all others (0). 
Work hours mismatch. To assess work hours mismatch, we asked: "Would you prefer to have more hours, fewer hours, or the current hours you work at your job?" We contrast the modal category of "current hours" with a category that includes both "more hours" and "fewer hours" and label this as "work hours mismatch" in our analyses (see Lyness et al. 2012). Our rationale for combining these categories is based on separate analyses (not shown) that reveal similar patterns for both groups of individuals in comparison to those who preferred their current work hours.

Job pressure. We use three items that are similar to other research on related themes like "pressure," "overwork," or “quantitative demands" (see Schieman 2013). The items ask about the frequency of the following in the past three months: "Felt overwhelmed by how much you had to do at work?" "Had to work on too many tasks at the same time?" "The demands of your job exceeded the time you have to do the work?" Response choices are coded: "never" (1), "rarely" (2), "sometimes" (3), "often" (4), and "very often" (5). We averaged the items; higher scores indicate more job pressure $(\alpha=.85)$.

\section{Job-Related Resources}

Schedule control. We use two items to measure schedule control: The first item asks: "Who usually decides when you start and finish work each day?" "Someone else" is coded 1, "you are able to decide within limits" is coded 2, and "you are entirely free to decide" is coded 3 (Lyness et al. 2012). A second item asks: "How much control do you have in scheduling your work hours?" Original response choices are coded "none" (1), "very little" (2), "some” (3), "a lot" (4), and “complete control" (5). To combine the items, we recoded the latter's response choices as: $1=$ "none or very little control," 2 = "some or a lot," and 3 = "complete control." We then summed these items; higher scores indicate more schedule control $(\alpha=.75)$. 
Job autonomy. To assess job autonomy, participants were asked the extent that they agree or disagree with the following statements: "I have the freedom to decide what I do on my job," "It is basically my own responsibility to decide how my job gets done," and "I have a lot of say about what happens on my job." Response choices are coded "strongly disagree" (1), "somewhat disagree" (2), "somewhat agree" (3), and "strongly agree" (4). We averaged responses to create the index; higher scores reflect more autonomy $(\alpha=.78)$. These items are similar to those of other studies (Grotto and Lyness 2010).

Job authority. We use responses to three items to assess job authority: "Do you supervise or manage anyone as part of your job?" "Do you influence or set the rate of pay received by others?"; "Do you have the authority to hire or fire others?" To create mutually exclusive classification categories, we followed the procedures in other recent research (Elliott and Smith 2004; Smith 2012). Individuals who responded "no" to all three items are classified as having no authority (the reference group). Those who responded "yes" only to the "supervise or manage" item are classified as having supervisory authority. Those who responded "yes" only to the "set the rate of pay" and/or the "hire or fire others" item are classified as having sanctioning authority. Those individuals who had both supervisory and sanctioning authority are classified as having managerial authority.

Challenging work. Five items measure challenging work: "My job requires that I keep learning new things," "My job requires that I be creative," "My job lets me use my skills and abilities," "The work I do on my job is meaningful to me," and "I get to do a lot of different things on my job." These items blend interrelated themes that have been referred to as "creative work," "nonroutine work," "skill utilization," and "learning possibilities" (Bakker and Geurts 2004; Mirowsky and Ross 2003a; Schieman and Young 2010b). Response choices are coded "strongly disagree" (1), "somewhat disagree" (2), "somewhat agree" (3), and "strongly agree" (4). We averaged responses; higher scores reflect more challenge $(\alpha=.78)$. 


\section{Work-Family Interface Measures}

Work contact. The frequency of work contact is based on responses to three items: "How often were you called about work-related matters when you were not at work?" "How often did you read job-related email or text messages when you were not at work?" "How often did you contact people about work-related matters when you were not at work?” (Families and Work Institute 2008; Schieman and Glavin 2008; Voydanoff 2005). Participants were asked about these activities during the past 3 months: "never" (1), "rarely" (2), “sometimes" (3), “often” (4), and "very often” (5). Responses are averaged to create the index; higher scores indicate more work contact $(\alpha=.78)$.

Family contact. The frequency of family contact is based on responses to two items: "How often did family members contact you during your work hours?" and "How often did you contact family during your work hours?” Participants were asked about these activities during the past 3 months: "never" (1), "rarely" (2), “sometimes" (3), “often” (4), and "very often” (5). Responses are averaged to create the index; higher scores indicate more family contact $(\alpha=.80)$.

Work-to-family conflict. We use four commonly used items from the NSCW to measure work-to-family conflict (Families and Work Institute 2008; Galinsky, Aumann, and Bond 2008; Voydanoff 2007). The items ask study participants how often in the last three months they have experienced the following: "not had enough time for the important people in your life because of your job," "not have the energy to do things with the important people in your life because of your job," "work kept you from doing as good a job at home as you could," and "job kept you from concentrating on important things in your family or personal life." Response choices are "never" (1), "rarely" (2), "sometimes" (3), "often" (4), and "very often" (5). We averaged items; higher scores indicate more work-to-home conflict $(\alpha=.89)$.

Family-to-work conflict. Four items ask study participants how often in the last three months they have experienced the following: "family or personal life kept you from doing as good a job at 
work as you could," "family or personal life kept you from concentrating on your job," "did not have enough time for your work because of your family or personal life," and "family or personal life drained you of the energy you needed to do your job." These are also commonly used and published items in the work-family literature (Families and Work Institute 2008; Galinsky et al. 2008; Young and Schieman 2012; Voydanoff 2007). Response choices are "never" (1), "rarely" (2), “sometimes" (3), “often" (4), and "very often" (5). We averaged items such that higher scores indicate more family-to-work conflict $(\alpha=.86)$.

\section{Control Variables}

We adjust for gender, age, marital status, the presence of children at home, and work in a for-profit organization because some research has suggested their influence on the sense of mastery, as well as their potential link to some of our focal independent variables (Ross and Mirowsky 2013; Schieman and Plickert 2008). We use dummy codes for men (0) and women (1). Age is coded in years. Individuals who are married or living with a partner are coded 1 , all others are coded 0 . We also include the total number of children younger than age 18 living at home. Finally, we use dummy codes for individuals working in a "for-profit" occupation (coded 1) compared to all others-_"non-profit," "government," and the "self-employed" (0). Appendix Tables A and B (respectively) report descriptive statistics and correlations among our focal measures of work conditions and aspects of the work-family interface.

\section{Plan of Analyses}

Using ordinary least squares (OLS) regression techniques, our analyses proceeds in seven models. First, model 1 in Table 1 tests the association between education and mastery, net of the basic control variables described above. Subsequent models separately include the following sets of 
variables: (2) income, occupation, and economic hardship; (3) job-related demands; (4) job-related resources; (5) demands and resources simultaneously; (6) work-family role-blurring activities; and (7) WFC and FWC. The progressive adjustments that we use in these models follow the logic and rationale described by Mirowsky (2013). These models are explicitly designed to test the demands, resources, and the stress of higher status hypotheses. Our decision to enter variables in these particular sets is motivated by an interest in their independent contributions to mastery as well as their net influences after having accounted for the others. This analytical approach of progressive adjustment in regression analyses can explain observed associations or reveal suppressed effects in which coefficients change direction or become stronger (Mirowsky 2013; Schieman 2010). While we recognize that other sequences of models are possible, we test these particular models because (a) we are interested in the ways that each job demand or resource is associated with mastery, and (b) we expect that their interrelationships might reveal overlapping influences on mastery.

\section{RESULTS}

Model 1 of Table 1 demonstrates that higher levels of educational attainment are associated with higher levels of mastery. Specifically, compared to those with a high school degree (the reference group), individuals with a 4-year college/university degree or a graduate degree (MA or Ph.D.) have higher average levels of mastery. Panel A of Figure 2 shows the predicted educationbased differences in mastery net of only basic control variables.

\section{[INSERT TABLE 1 AND FIGURE 2 ABOUT HERE]}

Model 2 adds personal income, occupation, and economic hardship. First, we find a remarkably linear pattern of differences among the income group comparisons, with each successive increase in income category being associated with higher levels of mastery. However, individuals in higher status occupations do not report more mastery than their peers in the other 
occupation groups. This is largely due to the higher income among executives and professionals. Third, economic hardship is associated negatively with mastery. Collectively, of the four indicators of SES, income has the largest total association with mastery—above and beyond its connection with education, occupation, and economic hardship. Moreover, and unexpectedly, the inclusion of these other indicators of SES fully accounts for the education-based differences that we observed in model 1; separate analyses (not shown) indicate that income accounts for most of this reduction. Panel B of Figure 2 shows the predicted education-based differences net of other forms of SES. As shown in model 3, people who work long hours report higher mastery (not lower mastery, as was predicted by the demands hypothesis). On the other hand, individuals who report work hours mismatch tend to report lower mastery compared to those who describe their current hours as desirable. Separate analyses (not shown) indicate that the inclusion of hours mismatch reveals a suppression effect of long work hours, with the latter's coefficient becoming positive and significant only after taking into account the positive association between long hours and hours mismatch. In addition, model 3 indicates that job pressure is associated negatively with masterynet of long hours and hours mismatch. Comparing models 2 and 3, the inclusion of these three jobrelated demands increase some of the education-, income-, and occupation-based differences; this is most evident among the two lowest income groups. Were it not for their greater exposure to these demands — especially job pressure —individuals in the second lowest income group would tend to report even greater mastery compared to those in the lowest earning group. These suppression patterns are consistent with the stress of higher status hypothesis: Elevated exposure to stressors offsets the psychosocial benefits of higher status, even among those workers who occupy the lower rungs of the earnings ladder. In addition, the adjustment for job demands accounts for 39 percent of the economic hardship coefficient, although it remains statistically significant. 
The inclusion of job resources in model 4 reveals several important patterns. First, schedule control, job autonomy, and challenging work are associated with more mastery. In general, these patterns are consistent with the resource hypothesis - although it is noteworthy that job authority is unrelated to mastery. Separate analyses (not shown) reveals that managers report significantly more mastery than workers with no authority $\left(\mathrm{b}_{\text {manager }}=.071, \mathrm{p}<.01\right)$ - but that difference is attributable to managers' higher earnings and other job resources. Collectively, these patterns indicate that the benefits associated with job authority are fully due to its link with pecuniary rewards and other resources. Yet, each of the other job resources has net positive influences on mastery. This suggests that job quality matters more strongly and independently than structural position in the workplace.

In model 5 with the simultaneous inclusion of job demands and resources, we observe several noteworthy changes from previous models. First, the positive association between working long hours and mastery (shown in model 3) is reduced to non-significance with the inclusion of job resources. Separate analyses (not shown) that enters each resource separately reveals that the reduction is mostly due to the shared overlap between long hours and challenging work. In other words, people who work longer hours also tend to have more challenging work - and this contributes to their higher level of mastery. Second, the positive association between schedule control and mastery (shown in model 4) is attributable to schedule control's negative association with work hours mismatch and job pressure. Lastly, comparing models 2 and 5, the negative association between economic hardship and mastery is no longer statistically significant net of both demands and resources; most of that reduction is attributable to the fact that people with more economic hardship also tend to report more job pressure and hours mismatch.

In model 6, we evaluate three different forms of role-blurring activities: work contact, family contact, and work-family multitasking. Neither work nor family contact initially appears to be associated with mastery. By contrast, however, multitasking is associated with a lower mastery. 
The final model includes both directions of work-family conflict, indicating that WFC and FWC are independently associated with lower levels of mastery. Separate analyses reveals that these two conditions have the largest net influence on mastery — and, more importantly_-both directions have almost entirely independent and unique effects. In addition, there are several other implications of the progressive adjustment of these forms of inter-role stress. First, a substantial suppression effect is produced for education-based differences in mastery. A comparison of the education contrasts across models 1 through 7 indicates that, at least initially, income explains why those in the two highest education groups report the most mastery. However, these groups' greater exposure to longer work hours, pressure, work-family multitasking, and WFC mask what would otherwise be even higher levels of mastery. In other words, the stressors associated with higher education offset its rewards. Conversely, most of income's positive association with mastery remains stable net of job demands, resources, and the work-family interface. These contrasting patterns highlight the different ways that two dimensions of stratification are relevant for mastery: Compared to income, education is coupled more closely with job attributes and conditions in the work-family interface.

Several other patterns emerge once we account for WFC and FWC. First, comparing models 5 and 7 indicates that individuals who report hours mismatch tend to have lower mastery mainly because of their experience of greater WFC and FWC. Second, the size of the coefficient for job pressure decreases from -.112 (model 6) to -.047 (model 7) or by about 58 percent, although it remains statistically significant at the .001 level. This indicates that excessive job pressure is associated with lower mastery in part because it elevates exposures to both WFC and FWC. Third, once we take into account the inter-role conflict that tends to coincide with work and family contact, both work contact and family are associated positively with sense of mastery. To illustrate the stronger pattern of the two, Panel A of Figure 3 shows the relationship between family contact and mastery prior to adjustments for WFC and FWC; Panel B shows that same relationship with 
these adjustments. The patterns in these two panels reveal that if we partial out the effect of conflict in the work-family interface, there is a net positive association between family contact and mastery. Fourth, the negative association between multitasking and mastery occurs through its association with WFC and FWC. These adjustments reduce the coefficient for multitasking from -.051 (model 6) to -.012 (model 7), or by 76 percent, and the effect of multitasking is no longer statistically significant. Panel A of Figure 4 shows the relationship between multitasking and mastery prior to the adjustment for WFC and FWC; Panel B shows that same association with these adjustments. The comparison of the patterns in these two panels illustrates the ways that conflict in the workfamily interface helps to explain why work-family multitasking is associated with lower mastery.

\section{[INSERT FIGURES 3 AND 4 ABOUT HERE]}

Lastly, a few patterns among the control variables deserve brief mention. First, model 7 indicates that women report a higher level of mastery compared to men-but a comparison with earlier models indicates that this pattern is suppressed by the fact that women report more WFC and FWC. Second, age is associated negatively with mastery, but the higher earnings that come with age suppress that pattern. Third, having children at home is associated with less mastery because it tends to elevate FWC. Fourth, those who work in for-profit jobs tend to report less mastery because they tend to have more job demands and fewer resources. ${ }^{2}$

\footnotetext{
${ }^{2}$ A reviewer suggested that we use logistic regression to test models with mastery dichotomized at the mean. In separate analyses (not shown), we performed these analyses and found that the results are highly similar in terms of the net effects and the size and direction of the changes in the coefficients across models. Moreover, the sizes of the p-values shown in the models are highly similar for logistic versus OLS regression analyses. Two main patterns are different between the OLS and logistic regression models: (1) Among income comparisons, the $\$ 25,000$ or less is statistically different from the reference group in logistic regression (with lower mastery, $\mathrm{p}<.05$ ). By contrast, the $\$ 50,001$ to $\$ 75,000$ group is not statistically different from the reference group in logistic regression. (2) Work contact is only marginally significant $(\mathrm{p}=.057)$ in logisitic regression.
} 


\section{DISCUSSION}

Our study provides three main contributions to the literature on the social-structural determinants of mastery. First, we document that each of the main components of socioeconomic status - starting with education - have distinct total, indirect, and net associations with mastery. Second, job-related demands and resources have largely independent associations with mastery, but our analyses also reveal some key areas of overlap. Third, role-blurring activities in the workfamily interface - and their connections with WFC and FWC — offer unique expansions to the overall narrative of mastery, with a complex mix of unexpected explanatory and suppression effects discovered. We describe and interpret each of these observations below.

Prior research has repeatedly demonstrated that individuals with the highest levels of education and income tend to report higher average levels of mastery (Ross and Mirowsky 2013; Schieman and Plickert 2008). We replicate these patterns and then demonstrate two novel discoveries that expand upon prior results. First, the adjustment for income fully accounts for education-based differences. That is, at least initially it appears that those with a 4-year university or degree or advanced graduate degree report more mastery because of their higher earnings. Second, our analyses reveal new suppression patterns that are substantively meaningful. For example, the net education-based differences observed in our final model indicate that education is associated with higher levels of mastery net of job demands, resources, and conditions in the workfamily interface. The initial education-based contrasts that we documented prior to the set of progressive adjustments reappear in our final two models. Essentially, we demonstrate that the welleducated report more mastery because of their higher earnings - but their exposures to more role blurring activities and WFC conceal or offset what would otherwise be their even higher levels of mastery. These patterns are quintessentially at the core of the stress of higher status hypothesis: Advanced education is associated with some forms of stressors that detract from, dampen, or offset 
its psychosocial rewards. However, these patterns are not observed for the other features of SES. The remaining net positive effect of education might pertain to the ways that education equips individuals with greater confidence, self-assurance and skills to meeting problems with thought, action, and persistence (Ross and Mirowsky 2013).

Collectively, these observations further underscore that the pathways that connect education to mastery are different from those for income or economic hardship. This contrast is important because it elaborates on the relevance of SES and the theoretical mechanisms of their influence. Unlike education, for example, we observe that income has a relatively stable association with mastery - with the exception of net differences between those in the two lowest income groups. This is important because it shows that the stress of higher status predictions are relevant across all levels of status inequality; the stress of higher status is not simply an argument about "high status." The fact that the positive link between income and mastery is suppressed by greater stress exposure at the lowest levels of income is a compelling new contribution in this regard. In addition, however, it is also surprising that income's positive association with mastery is largely independent of job demands, resources, and conditions in the work-family interface. On the other hand, economic hardship undermines mastery mainly because of its shared influence with job pressure. Net of education and income, we demonstrate that economic hardship's negative association with mastery is mostly attributable to its overlap with job-related demands - especially job pressure. Economic hardship plays a central role in the psychological functioning of individuals (Mirowsky and Ross 2003). Here, we demonstrate why matters for the sense of mastery. The connection with socialstructural conditions in the workplace provides central clues, with the bulk of the impact suggesting that those individuals who feel economic hardship are the same ones who feel overwhelmed by the amount of work they must do and the amount of time allotted for it. 
We also advance prior evidence about the connection between work and mastery by elaborating on the direct and indirect ways that job demands and resources are influential (e.g., Ross and Mirowsky 2013; Schieman and Plickert 2008). First and foremost, excessive pressure is the primary job demand that undermines mastery — and more than half of its influence is indirect through its link to higher levels of WFC. Similarly, hours mismatch is associated with lower mastery because of its link to role blurring and inter-role conflict. Taken together, these observations for job pressure and hours mismatch are consistent with the demands hypothesis.

By contrast, the influence of the other job demand — long work hours—suggests a different narrative. Here, we observe a net positive association between long work hours and mastery-but that becomes evident only after accounting for the fact that people who work long hours are at a higher risk of work hours mismatch. Our analyses then demonstrate that the net positive influence of long hours is attributable primarily to its link with more challenging work. We then further elaborate on this storyline by showing that were it not for the increased WFC that tends to come with it, working long hours would have an overall net positive link with mastery. Collectively, these patterns indicate that there is something beneficial about long work hours for mastery - perhaps an enhanced level of engagement or commitment to work — but that is only evident after we have accounted for the downsides of long hours. The progressive adjustments provide one illustration of the complex interplay between job demands and resources in the shaping of mastery-observations that further complicate and elaborate on the predictions of the demands and resources hypotheses.

Our analyses also extend previous research by differentiating among the four job-related resources. First, job autonomy stands out because of its net and indirect influence. Specifically, people with job autonomy report more mastery — a pattern that reinforces prior research (e.g., Ross and Mirowsky 2013; Schieman and Plickert 2008). However, we demonstrate that a substantial amount of autonomy's influence is attributable to link with lower levels of job pressure and WFC. 
By contrast, challenging work is associated positively with mastery and its influence is almost entirely independent of other job attributes and conditions in the work-family interface. In addition, schedule control's positive influence is entirely due to its link with a lower risk of work hours mismatch. Finally, and somewhat surprisingly, job authority is unrelated to mastery. This contrasts sharply with the notion that higher levels of power and influence in key role domains should be empowering and instill a sense of causal effectiveness. The specific reasons why job authority does not matter for mastery remain unknown. Based on previous studies, however, we suspect that part of the explanation might be due to the higher levels of interpersonal conflict in the workplace that tends to come with elevated levels of authority (Mirowsky and Ross 2003; Schieman and Reid 2009). This speculative point underscores the notion that the stress associated with higher status might be suppressing the psychosocial resources that tend to accrue to people with power at work. In other words, those with more job authority - a key form of job control and status - also tend to encounter elevated levels of some forms of stressors that might detract from the sense of mastery.

Of the three main contributions of our study, we believe that the findings related to the work-family interface are perhaps the most provocative — and somewhat unexpected. First and foremost, we discover the both directions of inter-role conflict—-work-to-family and family-towork - have independent and negative associations with the sense of personal mastery; these are the two strongest predictors of mastery. Second, higher levels of exposure to WFC and FWC fully contribute to the lower mastery among individuals who frequently engage in multitasking. This pattern explicitly demonstrates the downsides of role blurring for psychological functioning; moreover, it provides clues as to why previous studies show negative consequence of role-blurring activities for stress in the work-family interface (Schieman and Young 2010a; Voydanoff 2005).

Our observations for the two other forms of role blurring — work and family contact— provide a richer narrative about potential underling processes. Specifically, once we take into 
account the inter-role conflict that tends to coincide with work and family contact, both forms of role blurring are associated positively with sense of mastery. One interpretation of these suppression patterns involves the possibility that both forms of contact have elements that contribute to a sense of causal importance and effectiveness. When individuals are contacted about work-related matters outside of regular hours, there are clear downsides in terms of WFC (Glavin and Schieman 2010; Schieman and Glavin 2008; Voydanoff 2005). However, net of those downsides, frequent work contact might also enhance the sense that workers are important, influential, committed, and perhaps even more productive. Given that those with higher statuses tend to report work contact (Schieman and Glavin 2008, 2014), these processes reflect underlying dynamics predicted by the stress of higher status thesis. Likewise, when individuals engage in contact with family members while they are at work, there are downsides in terms of FWC. Once we have accounted for that, however, what remains appears to produce a positive link between frequent family contact and mastery. Family contact might have more socially integrative elements that enhance other psychosocial resources—but these benefits are only evident after we have accounted for the potentially disruptive aspects of frequent family contact. We are currently conducting in-depth interviews with a selection of these same study participants to probe these complex processes and elaborate on their meanings, causes, and consequences. This will shed light on the nature of work and family contact and its implications for stress in the work-family interface - and ultimately, psychological functioning.

Several study limitations deserve brief mention. First, the analyses are based on crosssectional data. While this limits our capacity to make definitive statements about causal direction, it does not diminish the discovered patterns and their links to theoretical perspectives. A related issue involves the claim that work conditions and the work-family interface represent concurrent socialstructural arrangements. In this sense, for example, one job attribute (e.g., pressure) does not 
necessarily occur before or after another job attribute (e.g., autonomy). However, with a series of progressive adjustments following the procedures (and rationale) outlined by Mirowsky (2013), we seek to differentiate among these conditions. To reiterate, out aim is not to make a strong case for causal ordering. Rather, we seek to document basic social patterns in mastery and then illustrate how other conditions might alter those estimates. We are currently engaged in the first of a series of follow-up interviews of these same study participants. Once complete, these additional data will allow us to more adequately track changes over time. For now, these initial estimates are intended to provide baseline patterns that can be used as a framework for more elaborate future analyses.

Another related challenge involves the possibility of selection effects. For example, individuals with higher levels of WFC or FWC may be more likely to select out of the workforce. They are therefore underrepresented in our sample. The question becomes: If this occurs, how influential or problematic is it for the estimates that we present here? Selection effects of this type could cause us to (a) underestimate the negative association between inter-role conflict and mastery, especially if those with the highest levels of mastery are better able to withstand the deleterious consequences; or (b) underestimate the ways that higher levels of SES, especially education, have net positive associations with mastery. Ultimately, we hope to be able to address these issues in future analyses with multiple waves of interview and richer qualitative data-essentially, we will seek to develop a clearer picture of how these selection effects play out over time among workers, and trace the impact of and implications for levels of mastery in these processes.

A third limitation and key area for future inquiry involves further investigation of potential contingencies in the observed patterns. Two social statuses — gender and age — could be more focal in future analyses. We opted in our analyses, however, to label these as "control variables" because we wanted to focus on SES, work, and the work-family interface - as well as the rather daunting scope of theoretical and empirical analyses required for possible gender and age contingencies. 
However, these are critically important next steps for research, and we plan on addressing them in the following ways. First, in the case of gender, it would be revealing to examine the determinants of mastery among men and women in dual-earner households with children. We have the unique capacity to assess the nature and division of household labor as well as childcare. As workers navigate the work-family interface, these aspects of the household might have different consequences for women and men. At this juncture, age might also be relevant as it relates to the life course. Some of the challenges of the work-family interface-and the particular configuration of job demands and resources - might be sharper for younger workers who are embarking on developments in both career and family stages. To reiterate, the objectives in this paper do not intend to dismiss these potential contingences. Rather, we have sought to provide a broader aggregate portrait of the social-structural determinants of mastery upon which more refined and nuanced analyses can build - including tests for complex contingencies.

To conclude, decades of scholarship have underscored the importance of mastery in the stress process. Sociologists continue to learn about the social structural arrangements that influence this key resource. Our study advances that knowledge—-with an elaboration of a narrative around different dimensions of socioeconomic status and their connections to conditions in the workplace and the work-family interface. Like Americans, most Canadians feel that their life chances are under their own control - and most reject the notion that fate dictates the events and outcomes in their lives (Ross and Mirowsky 2013). The observations presented here indicate that these selfconceptions are not randomly distributed in the population but rather intricately linked to key features of social life-especially those linked to SES, work, and the work-family interface. 


\section{REFERENCES}

Babbie, Earl. 2007. The Practice of Social Research. 11th edition. Belmont, CA: Wadsworth.

Bakker, Arnold B. and Sabine A.E. Geurts. 2004. "Toward a dual-process model of work-home interference." Work and Occupations 31:345-366.

Bakker, Arnold B. and Eva Demerouti. 2007. "The Job Demands-Resources Model: State of the Art.” Journal of Managerial Psychology 22:309-328.

Batt, Rosemary and Mary Valcour. 2003. "Human Resources Practices as Predictors of WorkFamily Outcomes and Employee Turnover." Industrial Relations 42: 189-220.

Beehr, Terry A., Katherine M. Glaser, Kristopher G. Canali, Dee A. Wallwey. 2001. "Back to the basics: Re-examination of demand control theory of occupational stress." Work \& Stress 15: 115130.

Becker, Gary S. 1993. Human Capital: A Theoretical and Empirical Analysis, with Special Reference to Education. $3^{\text {rd }}$ edition. Chicago, University of Chicago Press.

Böheim, Réne and Taylor P. Mark. 2004. "Actual and preferred working hours.” British Journal of Industrial Relations 42(1): 149-166.

Boswell, Wendy R. and Julie B. Olson-Buchanan. 2007. "The Use of Communication Technologies after Hours: The Role of Work Attitudes and Work-Life Conflict." Journal of Management 33:592610.

Chelsey, Noelle. 2005. "Blurring Boundaries? Linking Technology Use, Spillover, Individual Distress, and Family Satisfaction." Journal of Marriage and the Family 67:1237-1248.

Clark, Sue C. 2000. "Work/Family Border Theory: A New Theory of Work/Family Balance." Human Relations 53:747-770.

Curtin, Richard, Stanley Presser, and Eleanor Singer. 2000. "The Effects of Response Rate Changes on the Index of Consumer Sentiment." Public Opinion Quarterly 64:413-28.

Demerouti, Evangelia, Arnold B. Bakker. 2011. "The Job Demands-Resources Model: Challenges for Future Research." South African Journal of Industrial Psychology 37:1-9.

Department of Finance Canada. 2014. "Jobs Report: The State of the Canadian Labor Market." Retrieved April 23, 2014 (http://www.budget.gc.ca/2014/docs/jobs-emplois/pdf/jobs-emploiseng.pdf)

Duxbury, Linda, Sean Lyons, and Christopher Higgins. 2008. "Too Much To Do, and Not Enough Time: An Examination of Role Overload." Pp.125-140 in Handbook of Work-Family Integration: Research, Theory, and Best Practices, edited by Karen Korabik, Donna S. Lero, and Denise L. Whitehead. Burlington, MA: Elsevier.

Elliott, James R. and Ryan A. Smith. 2004. "Race, gender, and workplace power." American Sociological Review 69:365-386. 
Employment and Social Development Canada. 2014. "Indicators of Well-being in Canada: Work Unemployment rate.” Retrieved April 23, 2014 (http://www4.hrsdc.gc.ca/.3ndic.1t.4r@_

eng.jsp?iid=16)

Families and Work Institute. (2008). National study of the changing workforce. New York: Alfred P. Sloan Foundation.

Galinsky, Ellen, Kerstin Aumann, and James Bond. 2008. "Times are Changing: Gender and Generation at Work and at Home." The National Study of the Changing Workforce. New York, NY: Families and Work Institute.

Glavin, Paul and Scott Schieman. 2010. "Interpersonal Context at Work and the Frequency, Appraisal, and Consequences of Boundary-Spanning Demands.” The Sociological Quarterly 51:205-225.

Glavin, Paul and Scott Schieman. 2012. "Work-Family Role Blurring and Work-Family Conflict: The Moderating Influence of Job Resources and Job Demands." Work and Occupations 39:71-98.

Greenhaus, Jeffrey H. and Saroj Parasuraman. 1987. "A Work-Nonwork Interactive Perspective of Stress and its Consequences.” Journal of Organizational Behavior Management 8:37-60.

Grotto, Angela and Karen Lyness. 2010. “The Costs of Today's Jobs: Job Characteristics and Organizational Supports as Antecedents of Negative Spillover.” Journal of Vocational Behavior 76:395-405.

Groves, Robert M. 2006. "Nonresponse Rates and Nonresponse Bias in Household Surveys."Public Opinion Quarterly 70:646-75.

Hunter, Alfred A. 1988. "Formal Education and Initial Employment: Unraveling the Relationships between Schooling and Skills over Time." American Sociological Review 53(5):753-65.

Jacobs, Jerry A. and Kathleen Gerson. 2004. The Time Divide: Work, Family and Gender Inequality. Cambridge: Harvard University Press.

Karasek, Robert A. 1979. "Job Demands, Job Decision Latitude, and Mental Strain: Implications for Job Redesign.” Administrative Science Quarterly 24:285-308.

Karasek, Robert A., and T. Theorell. 1990. Healthy Work: Stress, Productivity, and the Reconstruction of Working Life. Basic Books, New York, NY.

Karasek, R., Brisson, C., Kawakami, N., Houtman, I., Bongers, P., Amick, B., 1998. The job content questionnaire (JQC): An instrument for internationally comparative assessments of psychosocial job characteristics. Journal of Occupational Health Psychology 3, 322-355.

Kerchkhoff, Alan C., Stephen W. Raudenbush and Elizabeth Glennie. 2001. "Education, Cognitive Skill, and Labor Force Outcomes." Sociology of Education 74(1):1-24.

Kohn, Melvin L. and Carmi Schooler. 1982. "Job conditions and personality: A longitudinal assessment of their reciprocal effects." The American Journal of Sociology 87:1257-1286.

Low, Gail, Norah Keating, and Zhiwei Gao. 2009. "The Differential Importance of Personal and 
Environmental Resources to Older Canadians." Canadian Review of Sociology 46(4): 371-392.

Lyness, Karen S., Janet C. Gornick, Pamela Stone, and Angela R. Grotto. 2012. "It's All about Control: Worker Control over Schedule and Hours in Cross-National Context." American Sociological Review 77(6): 1023-49.

Marx, Karl. [1852] 1983. "From the Eighteenth Brumaire of Louis Bonaparte." The Portable Karl Marx, edited by E. Kamenka. New York: Penguin.

Maume, David and Marcia L. Bellas. 2001. "The Overworked American or the Time Bind? Assessing Competing Explanations for Time Spent in Paid Labor." American Behavioral Scientist 44:1137-1156.

Merkle, Daniel and Murray Edelman. 2002. "Nonresponse in Exit Polls: A Comprehensive Analysis." Pp. 243-58 in Survey Nonresponse, edited by R. M. Groves, D. A. Dillman, J. L. Eltinge, and R. J. A. Little. New York: Wiley.

McLeod, Jane. 2013. "Social Stratification and Inequality" Pp. 229-253 in The Handbook of the Sociology of Mental Health, $2^{\text {nd }}$ Edition, edited by Carol. S. Aneshensel, Jo. C. Phelan, and Alex Bierman. New York: Springer.

Milliken, Frances. J. and Linda Dunn-Jensen. 2004. "The Changing Time Demands of Managerial and Professional Work: Implications for Managing the Work-Life Boundary." Pp. 43-59 in Work and Life Integration: Organizational, Cultural, and Individual Perspectives, edited by Ellen E. Kossek and Susan J. Lambert. Lawrence Erlbaum Associates.

Mirowsky, John. 2013. "Analyzing Associations Between Mental Health and Social Circumstances." Pp. 143-165 in The Handbook of the Sociology of Mental Health, $2^{\text {nd }}$ Edition, edited by Carol. S. Aneshensel, Jo. C. Phelan, and Alex Bierman. New York: Springer.

Mirowsky, John and Catherine E. Ross. 2003a. Social Causes of Psychological Distress. $2^{\text {nd }}$ edition, Hawthorne, New York: Aldine De Gruyter.

Mirowsky, John and Catherine E. Ross. 2003b. Education, Social Status, and Health. New Brunswick, N.J.: Aldine Transaction.

Moen, Phyllis and Yan Yu. 2000. "Effective Work-Life Strategies: Working Couples, Work Conditions, Gender, and Life Quality.” Social Problems 47:291-326.

Offer, Shira and Barbara Schneider. 2011. "Revisiting the Gender Gap in Time-Use Patterns: Multitasking and Well-Being among Mothers and Fathers in Dual-Earner Families." American Sociological Review 76:809-833.

Otterbach, Steffen. 2010. "Mismatches between Actual and Preferred Work Time: Empirical Evidence of Hours Constraints in 21 Countries." Journal of Consumer Policy 33(2): 143-161.

Pallas, Aaron M. 2003. "Educational Transitions, Trajectories, and Pathways." Pp. 16584. Handbook of the Life Course, edited by Jeylan T. Mortimer and Michael J. Shanahan. New York: Kluwer Academic/Plenum Publishers. 
Pearlin, Leornard I. and Carmi Schooler. 1978. "The Structure of coping." Journal of Health and Social Behavior 19(1): 2-21.

Pearlin Leonard I., Scott Schieman, Elena M. Fazio, Stephen C. Meersman. 2005. "Stress, Health, and the Life Course: Some Conceptual Perspectives". Journal of Health and Social Behavior 46: 205-219.

Pearlin, Leonard I., Kim Nguyen, Scott Schieman, and Melissa A. Milkie. 2007. "Life-Course Origins of Mastery Among Older People." Journal of Health and Social Behavior 48:164-179.

Pearlin, Leonard I., Alex Bierman. 2013. "Current Issues and Future Directions in Research into the Stress Process" Pp. 325-340 in The Handbook of the Sociology of Mental Health, $2^{\text {nd }}$ Edition, edited by Carol. S. Aneshensel, Jo. C. Phelan, and Alex Bierman. New York: Springer.

Tetyana Pudrovska, Scott Schieman, Leonard I. Pearlin, and Kim Nguyen. 2005. "The Sense of Mastery as a Mediator and Moderator in the Association between Economic Hardship and Health in Late-Life" Journal of Aging and Health 17:634-60.

Ross, Catherine E. and Barbara F. Reskin. 1992. "Education, Control at Work, and Job Satisfaction." Social Science Research 21: 134-48.

Ross, Catherine E. and John Mirowsky. 1992. "Households, Employment, and the Sense of Control." Social Psychology Quarterly 55: 217-35.

Ross, Catherine E. and John Mirowsky. 2013. "The Sense of Personal Control: Social-Structural Causes and Emotional Consequences." Pp. 379-404 in The Handbook of the Sociology of Mental Health, $2^{\text {nd }}$ Edition, edited by Carol. S. Aneshensel, Jo. C. Phelan, and Alex Bierman. New York: Springer.

Ross, Catherine E. and Marylyn P. Wright. 1998. “Women's work, men's work and the sense of control." Work and Occupations 25:333-355.

Schaufeli, William B. and Toon W. Taris. 2014. "A Critical Review of the Job DemandsResources Model: Implications for Improving Work and Health.” Pp. 43-68 in Bridging Occupational, Organizational and Public Health, edited by Georg F. Bauer and Oliver Hämmig. Springer: Netherlands.

Schieman, Scott. 2001. "Age, Education, and the Sense of Control: An Examination of the Cumulative Advantage Hypothesis." Research on Aging 23:153-78.

Schieman, Scott. 2010. "Suppression Effects in Social Stress Research and their Implications for the Stress Process Model.” Pp. 53-70 in Advances in the Conceptualization and Study of the Stress Process: Essays in Honor of Leonard I. Pearlin, edited by W.R. Avison, C. S. Aneshensel, S.

Schieman, and B. Wheaton. New York, NY: Springer.

Schieman, Scott. 2013. "Job-Related Resources and the Pressures of Working Life. Social Science Research 42:271-282. 
Schieman, Scott and Paul Glavin. 2008. "Trouble at the Border? Gender, Flexible Work Conditions, and the Work-Home Interface." Social Problems 55:590-611.

Schieman, Scott and Paul Glavin. 2011. "Education and Work-Family Conflict: Explanations, Contingencies, and Mental Health Consequences.” Social Forces 89(4):1341-1362.

Schieman, Scott, Yuko Kurashina, and Karen Van Gundy. 2006. "The Nature of Work and the Stress of Higher Status." Journal of Health and Social Behavior 47: 242-57.

Schieman, Scott and Gabriele Plickert. 2008. "How Knowledge is Power: Explaining the Association between Education and the Sense of Control." Social Forces 87: 153-84.

Schieman, Scott, Melissa Milkie, and Paul Glavin. 2009. "When Work Interferes with Life: The Social Distribution of Work-Nonwork Interference and the Influence of Work-Related Demands and Resources." American Sociological Review 74: 966-87.

Schieman, Scott and Sarah Reid. 2009. "Job Authority and Health: Unraveling the Competing Suppression and Explanatory Influences." Social Science and Medicine. Social Science and Medicine 69:1616-1624.

Schieman, Scott, and Heather A. Turner. 1998. "Age, Disability, and the Sense of Mastery." Journal of Health and Social Behavior 39:169-86.

Schieman, Scott and Marisa Young. 2010a. "The Demands of Creative Work: Implications for the Stress in the Work-Family Interface.” Social Science Research 39:246-59.

Schieman, Scott and Marisa Young. 2010b. "Is there a Downside to Schedule Control for the WorkFamily Interface?” Journal of Family Issues 31(10):1391-1414.

Smith, Ryan A. 2012. "Money, Benefits and Power: A Test of Glass Ceiling and Glass Escalator Hypotheses" The Annals of the American Academy of Political and Social Science. 639:1:148-171.

Statistics Canada. 2014. "Labor Force Survey, March 2014.” Retrieved April 23, 2014 (http://www.statcan.gc.ca/daily-quotidien/140404/dq140404a-eng.htm)

Tausig, Mark and Rudy Fenwick. 2011. Work and Mental Health in Social Context. Springer: New York.

Turner, R. Jay and Donald A. Lloyd. 1999. "The Stress Process and the Social Distribution of Depression." Journal of Health and Social Behavior 40:374-404.

U.S Bureau of Labor Statistics. 2014. "Labor Force Statistics from the Current Population Survey." Retrieved April 23, 2014 (http://data.bls.gov/timeseries/LNS14000000)

Valcour, Monique P., and Larry W. Hunter, 2005. "Technology, organizations, and work-life integration.” pp. 61-85 in Work and life integration: Organizational, cultural, and individual perspectives, edited by Ellen Kossek and Susan. J. Lambert. Mahwah, NJ: Lawrence Erlbaum Associates. 
Voydanoff, Patricia. 2005. "Consequences of Boundary-Spanning Demands and Resources for Work-to-Family Conflict and Perceived Stress." Journal of Occupational Health Psychology 10: 491-503.

Voydanoff, Patricia. 2007. Work, Family, and Community: Exploring Interconnections. Mahwah, NJ: Lawrence Erlbaum Associates.

Wallace, Jean. 2013. "Social Relationships, Well-Being, and Career Commitment: Exploring CrossDomain Effects of Social Relationships.” Canadian Review of Sociology 50(2): 135-153

Wallace, Jean and Marisa C. Young. 2010. "Work Hard, Play Hard?: A Comparison of Male and Female Lawyers' Time and Paid and Unpaid Work and Participation in Leisure Activities." Canadian Review of Sociology 47(1): 27-47

Walters, Vivienne and Margaret Denton. 1995. "Stress, Depression, and Tiredness among Women: The Social Production and Social Construction of Health." Canadian Review of Sociology 34(1): 53-69

Winship, Christopher and Larry Radbill. 1994. "Sampling Weights and Regression Analysis." Sociological Methods and Research 23:230-257.

Wooden, Mark, Diana Warren, and Robert Drago. 2009. "Working time mismatch and subjective wellbeing.” British Journal of Industrial Relations 47(1): 147-179.

Young, Marisa and Scott Schieman. 2012. "When Hard Times Take a Toll: The Distressing Consequences of Economic Hardship and Life Events within the Family Work Interface." Journal of Health and Social Behavior 53(1): 84-98. 
APPENDIX TABLE A. Descriptive Statistics $(N=5,576)$

\begin{tabular}{|c|c|c|c|}
\hline & $\begin{array}{l}\text { Mean or } \\
\text { Proportion }\end{array}$ & $\begin{array}{l}\text { Standard } \\
\text { Deviation }\end{array}$ & Range \\
\hline The Sense of Mastery & 2.922 & .604 & $1-4$ \\
\hline \multicolumn{4}{|l|}{ Socioeconomic Status } \\
\hline Less than High School & .074 & .262 & $0-1$ \\
\hline High School & .200 & .400 & $0-1$ \\
\hline Associate Degree & .123 & .328 & $0-1$ \\
\hline Some College & .158 & .365 & $0-1$ \\
\hline College Degree & .322 & .467 & $0-1$ \\
\hline Graduate Degree & .123 & .329 & $0-1$ \\
\hline$\$ 25,000$ or less & .267 & .443 & $0-1$ \\
\hline$\$ 25,001$ to $\$ 50,000$ & .315 & .465 & $0-1$ \\
\hline$\$ 50,001$ to $\$ 75,000$ & .184 & .388 & $0-1$ \\
\hline$\$ 75,001$ to $\$ 100,000$ & .109 & .312 & $0-1$ \\
\hline More than $\$ 100,000$ & .078 & .269 & $0-1$ \\
\hline Executive/Professional & .361 & .480 & $0-1$ \\
\hline Economic Hardship & .037 & .566 & $-1.142-6.585$ \\
\hline \multicolumn{4}{|l|}{ Job-Related Demands } \\
\hline Long Work Hours & .171 & .376 & $0-1$ \\
\hline Work Hours Mismatch & .463 & .499 & $0-1$ \\
\hline Job Pressure & 2.970 & 1.094 & $1-5$ \\
\hline \multicolumn{4}{|l|}{ Job-Related Resources } \\
\hline Schedule Control & 3.495 & 1.256 & $2-6$ \\
\hline Job Autonomy & 2.886 & .809 & $1-4$ \\
\hline No Authority & .500 & - & $0-1$ \\
\hline Supervisory Authority & .236 & - & $0-1$ \\
\hline Sanctioning Authority & .068 & - & $0-1$ \\
\hline Managerial Authority & .196 & - & $0-1$ \\
\hline Challenging Work & 3.287 & .681 & $1-4$ \\
\hline \multicolumn{4}{|l|}{ Work-Family Interface } \\
\hline Work Contact & 2.343 & 1.081 & $1-5$ \\
\hline Family Contact & 2.446 & .974 & $1-5$ \\
\hline W-F Multitasking & 1.997 & 1.168 & $1-5$ \\
\hline Work-to-Family Conflict & 2.473 & 1.000 & $1-5$ \\
\hline Family-to-Work Conflict & 1.816 & .763 & $1-5$ \\
\hline \multicolumn{4}{|l|}{ Basic Control Variables } \\
\hline Women & .477 & - & $0-1$ \\
\hline Age & 39.929 & 13.541 & $18-89$ \\
\hline Married/Cohabiting & .486 & - & $0-1$ \\
\hline Children at Home & .705 & - & $0-1$ \\
\hline Works at For-Profit & .527 & - & $0-1$ \\
\hline
\end{tabular}


APPENDIX TABLE B. Pair-wise correlations between focal variables $(\mathrm{N}=5,576)$

\begin{tabular}{lccccccccc}
\hline & 1 & 2 & 3 & 4 & 5 & 6 & 7 & 8 & 9 \\
\hline 1. Job pressure & 1.00 & & & & & & & & \\
2. Schedule control & -.07 & 1.00 & & & & & & & \\
3. Autonomy & -.05 & .51 & 1.00 & & & & & & \\
4. Challenging work & .11 & .25 & .48 & 1.00 & & & & & \\
5. Work Contact & .30 & .24 & .22 & .22 & 1.00 & & & & \\
6. Family Contact & .09 & .18 & .16 & .06 & .24 & 1.00 & & & \\
7. W-F Multitasking & .25 & .21 & .21 & .22 & .48 & .17 & 1.00 & & \\
8. W-F Conflict & .54 & -.13 & -.13 & -.04 & .33 & .15 & .30 & 1.00 & \\
9. F-W Conflict & .26 & .01 & -.03 & .01 & .20 & .20 & .31 & .42 & 1.00 \\
\hline All
\end{tabular}

All correlations larger than .04 are significant at $p<.01$ level. 
TABLE 1. Regression of Mastery on Job Demands, Resources, and WF Interface $(N=5,576)$

\begin{tabular}{|c|c|c|c|c|c|c|c|}
\hline & Model 1 & Model 2 & Model 3 & Model 4 & Model 5 & Model 6 & Model 7 \\
\hline \multicolumn{8}{|l|}{ Socioeconomic Status } \\
\hline Less than High School ${ }^{a}$ & -.084 & -.056 & -.062 & -.059 & -.062 & -.059 & -.056 \\
\hline Associate Degree $^{a}$ & .009 & -.012 & -.002 & -.015 & -.008 & -.009 & -.003 \\
\hline Some College $^{a}$ & .035 & .030 & .032 & .037 & .039 & .041 & .052 \\
\hline College Degree $^{a}$ & $.102 * * *$ & .046 & $.065 *$ & .051 & $.068 *$ & $.075^{*}$ & $.087 * *$ \\
\hline Graduate Degree $^{a}$ & $.143 * * *$ & .042 & .066 & .037 & .061 & $.074 *$ & $.090 * *$ \\
\hline$\$ 25,000$ or less ${ }^{b}$ & - & -.057 & $-.097 * * *$ & -.050 & $-.087 * *$ & $-.080 * *$ & $-.077 * *$ \\
\hline$\$ 50,001$ to $\$ 75,000^{b}$ & - & $.074 * *$ & $.082 * *$ & $.070 *$ & $.076 * *$ & $.076 * *$ & $.068 * *$ \\
\hline$\$ 75,001$ to $\$ 100,000^{b}$ & - & $.117 * * *$ & $.146 * * *$ & $.107 * *$ & $.134 * * *$ & $.134 * * *$ & $.124 * * *$ \\
\hline More than $\$ 100,000^{b}$ & - & $.194 * * *$ & $.204 * * *$ & $.168 * * *$ & $.176 * * *$ & $.174 * * *$ & $.143 * * *$ \\
\hline Executive/Professional & - & .041 & $.062 * *$ & .010 & .029 & .034 & .029 \\
\hline Economic Hardship & - & $-.071 * * *$ & $-.044 *$ & $-.066 * *$ & -.041 & -.038 & -.009 \\
\hline \multicolumn{8}{|l|}{ Job-Related Demands } \\
\hline Long Work Hours & - & - & $.059 *$ & - & .020 & .036 & $.060 *$ \\
\hline Work Hours Mismatch & - & - & $-.074 * * *$ & - & $-.056 * *$ & $-.050 *$ & -.021 \\
\hline Job Pressure & - & - & $-.119 * * *$ & - & $-.118 * * *$ & $.112 * * *$ & $-.045 * * *$ \\
\hline \multicolumn{8}{|l|}{ Job-Related Resources } \\
\hline Schedule Control & - & - & - & $.021 *$ & .010 & .012 & -.001 \\
\hline Job Autonomy & - & - & - & $.071 * * *$ & $.049 * *$ & $.053 * *$ & $.033 *$ \\
\hline Supervisory Authority ${ }^{c}$ & - & - & - & -.002 & .018 & .016 & .021 \\
\hline Sanctioning Authority ${ }^{c}$ & - & - & - & -.067 & -.033 & -.012 & -.017 \\
\hline Managerial Authority ${ }^{c}$ & - & - & - & -.044 & .018 & .025 & .034 \\
\hline Challenging Work & - & - & - & $.086 * * *$ & $.103 * * *$ & $.110 * * *$ & $.085 * * *$ \\
\hline \multicolumn{8}{|l|}{ Work-Family Interface } \\
\hline Work Contact & - & - & - & - & - & .009 & $.027 *$ \\
\hline Family Contact & - & - & - & - & - & .012 & $.038 * * *$ \\
\hline W-F Multitasking & - & - & - & - & - & $-.051 * * *$ & -.013 \\
\hline Work-to-Family Conflict & - & - & - & - & 一 & - & $-.127 * * *$ \\
\hline Family-to-Work Conflict & - & - & - & - & - & - & $-.146 * * *$ \\
\hline \multicolumn{8}{|l|}{ Basic Control Variables } \\
\hline Women & -.035 & -.005 & .027 & .002 & .027 & .029 & $.044 *$ \\
\hline Age & $-.002 * *$ & $-.004 * * *$ & $-.004 * * *$ & $-.005 * * *$ & $-.005 * * *$ & $-.005 * * *$ & $-.005 * * *$ \\
\hline Married/Cohabiting & $.104 * * *$ & $.081 * * *$ & $.089 * * *$ & $.077 * * *$ & $.083 * * *$ & $.076 * * *$ & $.074 * * *$ \\
\hline Children at Home & -.021 & $-.024 *$ & $-.022 *$ & $-.027 *$ & $-.026^{*}$ & $-.025^{*}$ & -.010 \\
\hline Works at For-Profit & $-.057 * *$ & $-.051 *$ & $-.043 *$ & -.018 & -.015 & -.023 & -.029 \\
\hline Constant & 2.977 & 3.036 & 3.393 & 2.523 & 2.911 & 2.891 & 3.233 \\
\hline$R^{2}$ & .035 & .054 & .103 & .083 & .127 & .134 & .203 \\
\hline
\end{tabular}

$* p<.05 ; * * p<.01 ; * * * p<.001$ (two-tailed test).

${ }^{a}$ Compared to high school degree or GED. ${ }^{b}$ Compared to $\$ 25,001$ to $\$ 50,000 .{ }^{c}$ Compared to no authority. Note: Unstandardized regression coefficients shown in table. 
FIGURE 1. Conceptual Framework

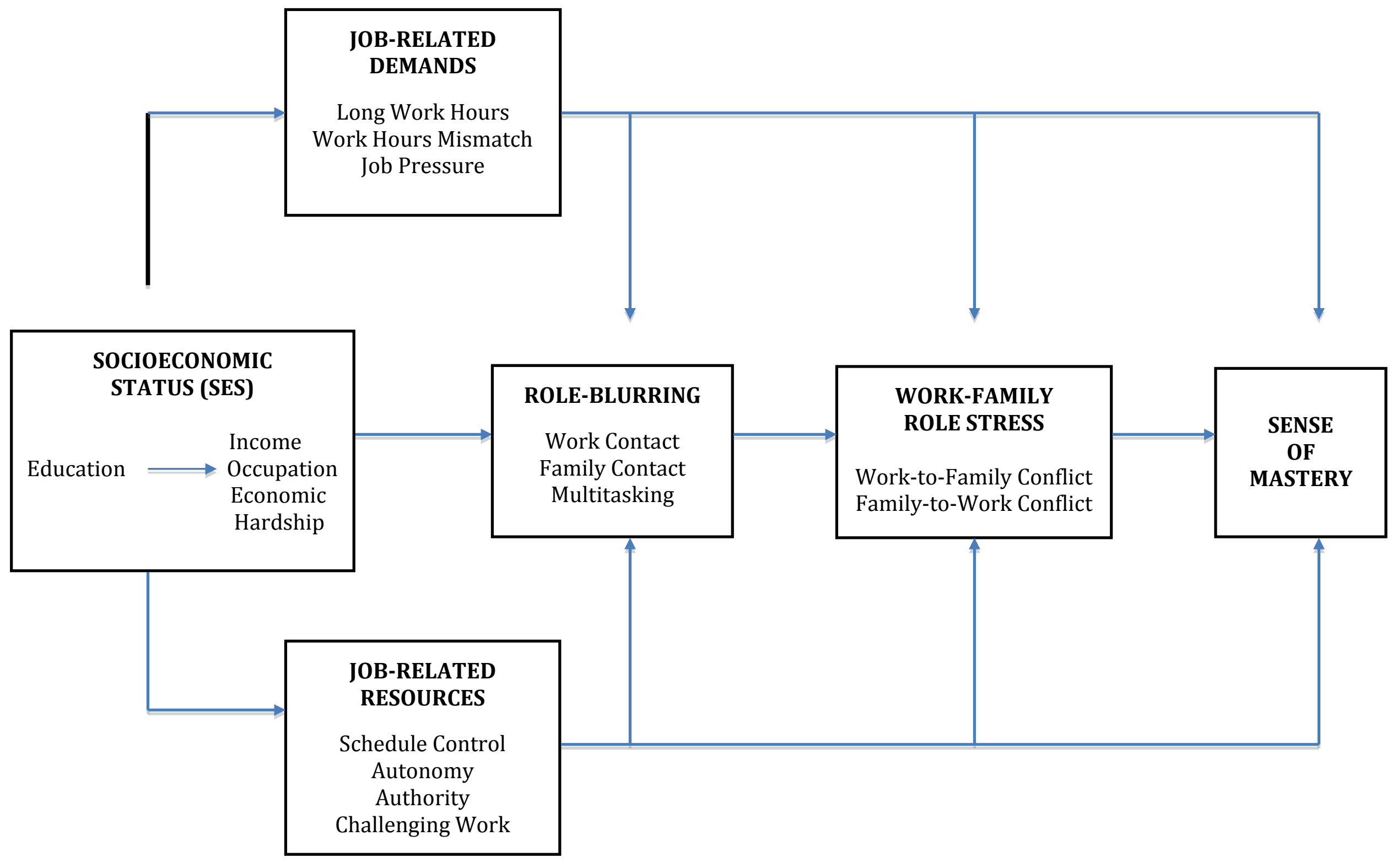


Figure 2. Education and Mastery
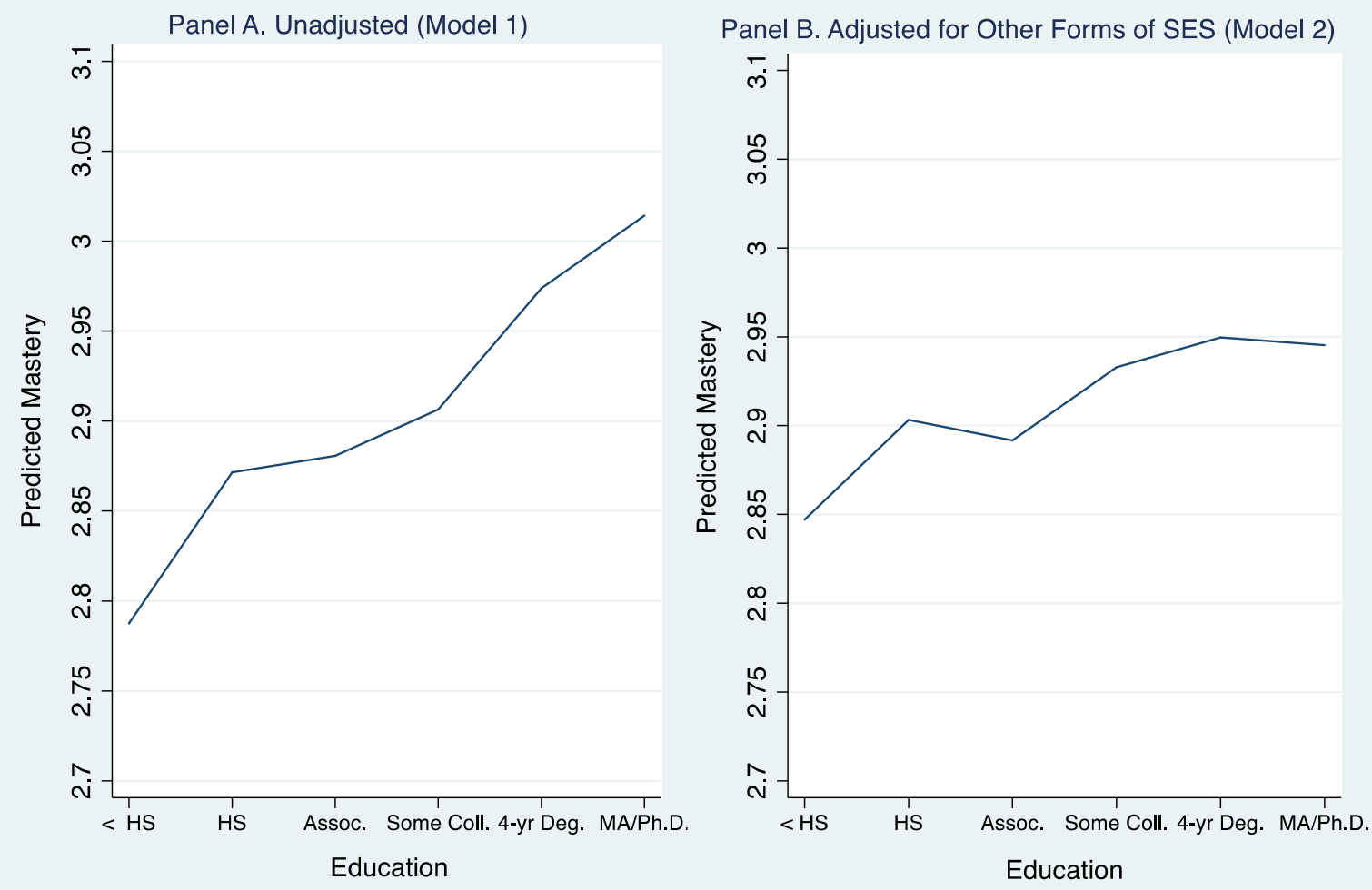
Figure 3. Family Contact and Mastery
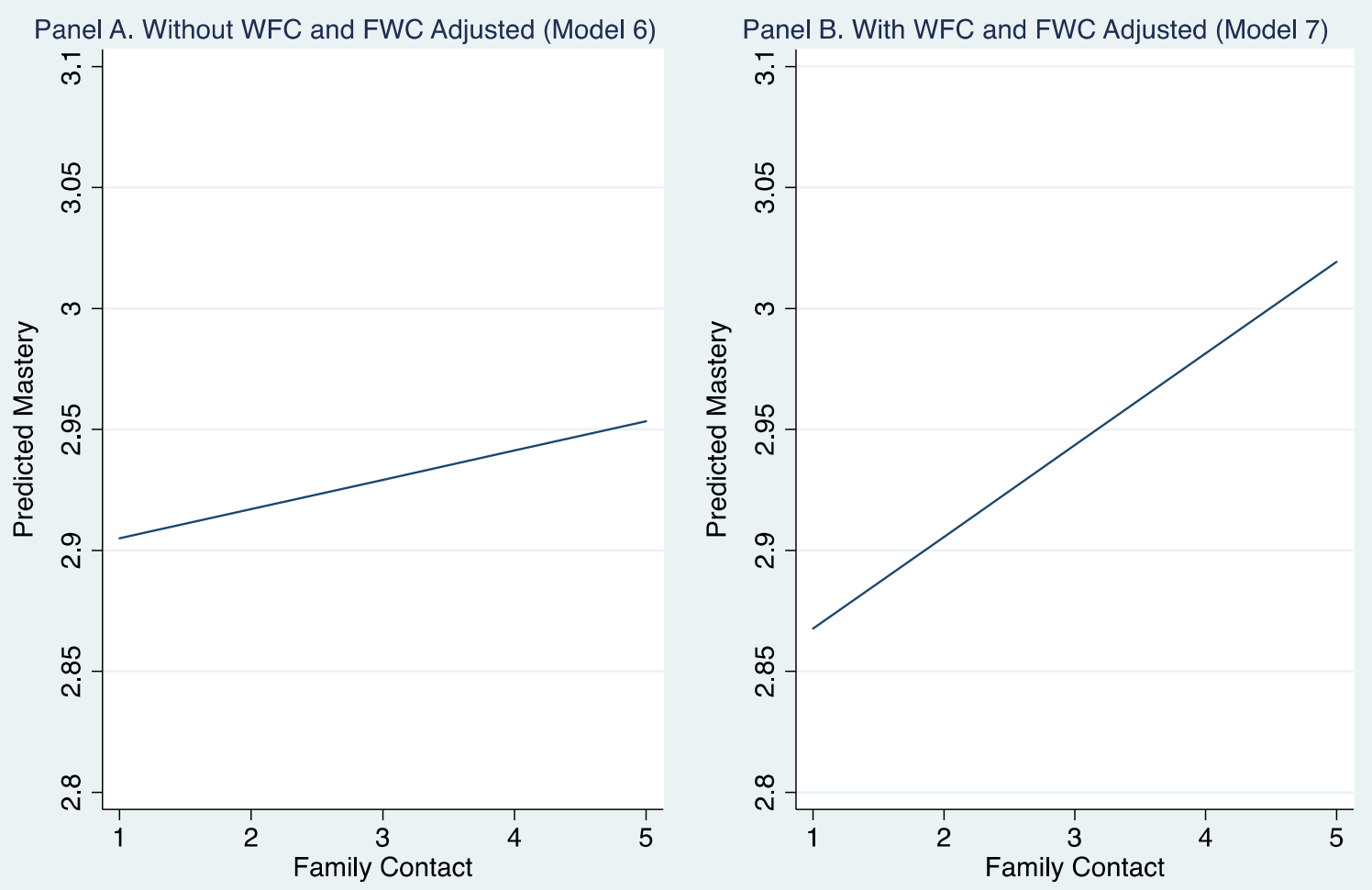


\section{Figure 4. Multitasking and Mastery}
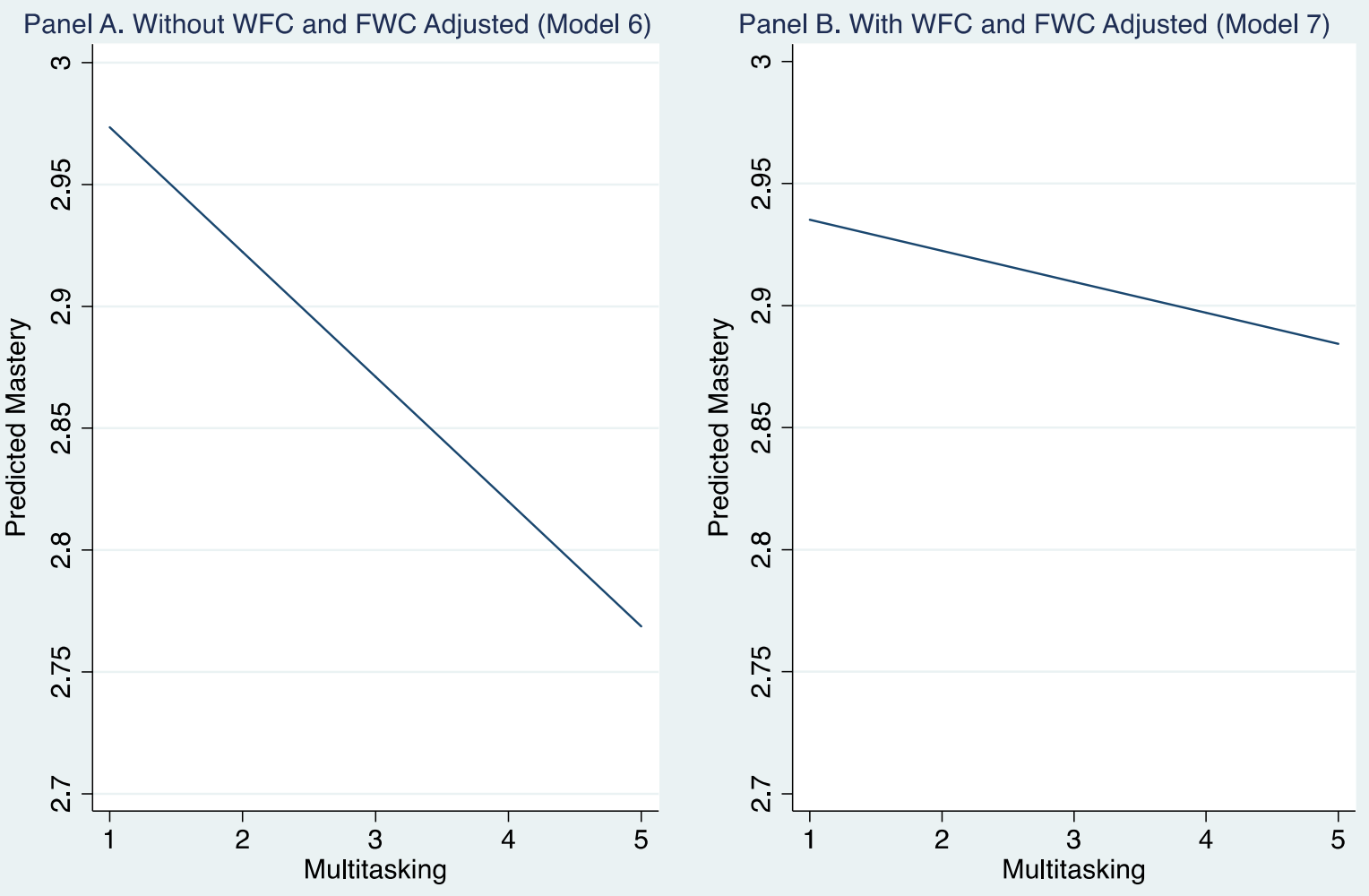